\title{
Atlas de imagens e seus intervalos. \\ Uma constelação de conceitos flutuantes
}

\section{Resumo}

À semelhança do Atlas de Mnemosyne definido por Warburg e investigado por DidiHuberman, este texto utiliza a ideia de constelação para tratar os intervalos entre visualidades como espaços capazes de gerar experiências singulares dentro dos processos investigativos. Ao entender a imagem como uma vivência, uma espécie de orquestração sensível e sensorial aberta num circuito de fenômenos conectados por experiências e tempos diversos, o artigo abre fendas para pensar a construção de sentidos para além dos rigores de cientificidade.

Palavras-chave: metodologia, visualidades, processo reflexivo

\section{Constellation of floating concepts.}

An atlas of images and their intervals

\begin{abstract}
Like Atlas Mnemosyne defined by Warburg and investigated by Didi-Huberman, this text uses the idea of constellation to treat the intervals between visualities as spaces capable of generating unique experiences within the investigative processes. By understanding the image as an experience, a kind of sensitive orchestration and sensory phenomena in an open connected by circuit experiments and several times, the article opens slits to think about the construction of meaning beyond the rigors of scientificity.
\end{abstract}

Keywords: methodology, visualities, reflective process

\section{I magens que transbordam das latas de Leite Ninho para os artigos acadêmicos}

Minha coleção de tampinhas de garrafa eu guardava em uma lata de Leite Ninho. Todas elas vinham com imagens de super-heróis impressas em sua parte interna. Bastava retirar aquela rodelinha de plástico - que nem existe mais - do fundo da tampinha para transformá-la em item de colecionador. As figurinhas de chiclete Ping Pong eram recortadas com precisão para fazer caber 10 em uma folha de papel sulfite colorido. Depois de coladas, o destino dado a elas era a pasta-catálogo (Figura 1) em uma sofisticação que nenhuma lata de leite poderá alcançar um dia.

Na parede ao lado da cama, cuidadosamente organizados e fixados com percevejos, saquinhos plásticos exibiam meus gibis favoritos. Em convivências ora harmoniosas, ora 
conflitantes, Homem-Aranha, Chico Bento, Recruta Zero e Tio Patinhas dividiam o mesmo espaço. As fitas $\mathrm{K} 7$ continham músicas do rádio em gravações escolhidas a dedo [e muita paciência]. Ao lado delas, ficavam as fitas VHS com capas fabricadas manualmente usando recortes de revistas de cinema. O que faltava na composição era completado com letras riscadas e lapidadas pelo designer gráfico que já morava em mim sem que eu o soubesse.

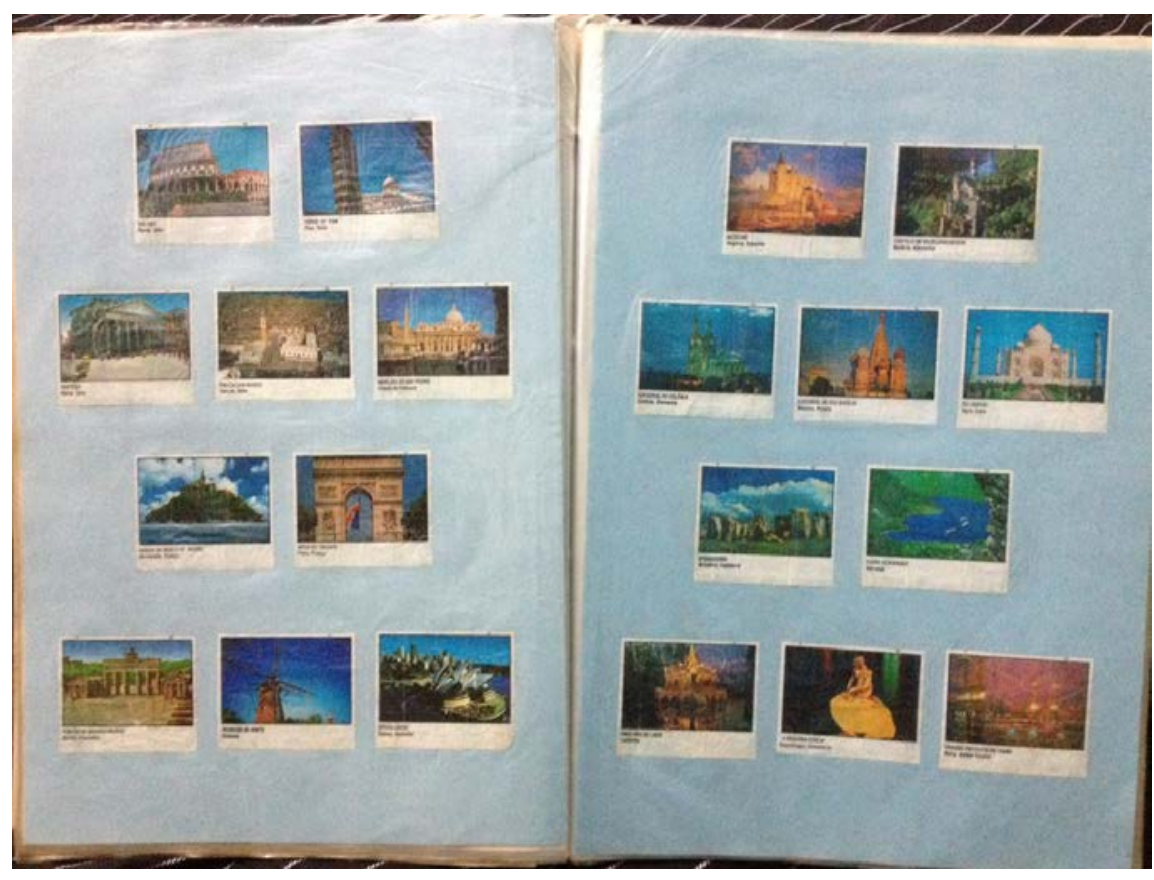

Figura 1 - Pasta catálogo que abriga minha coleção de figurinhas de chiclete (foto do autor).

Atualmente, como parte de um trabalho artístico, passei a registrar fragmentos de realidades. Comecei registrando um abraço ali, um descuido acolá e quando dei por mim, tinha um monte de instantes colecionados por aí. Numa espécie de epifania, resolvi reunir todos eles em um blog ${ }^{1}$. Pelas vias da simplicidade, minha coleção de instantes passou a ser um canto onde posso guardar sorrisos, conversas, olhares, encontros e sentidos.

Trago minhas memórias de colecionador para iniciar uma reflexão acerca de ajuntamentos e ordenações de visualidades como uma prática que sempre me acompanhou. Embora os objetos, as imagens, os sons e os instantes colecionados e seus significados me interessem, necessariamente não são eles o foco desse texto. Aqui eles funcionarão como parte de um sistema mais amplo onde a tessitura de uma espécie de mostruário pessoal e suas variadas disposições sugerem e proporcionam novos espaços onde o pensamento se move em vias múltiplas. Reunir visualidades em conjuntos

\footnotetext{
${ }^{1}$ http://colecaodeinstantes. blogspot.com.br/
} 
diversos é uma prática cotidiana e, dentro dos processos investigativos esse costume é cercado por questões de ordem metodológica que, obviamente, incita à reflexão. Como esses espaços "entre" imagens podem revelar experiências singulares? É possível organizar essas experiências de modo a permeá-las com sentidos para além das institucionalidades acadêmicas?

\section{Entre a suspensão e o movimento. 0 que há entre as estrelas?}

Os ideais de cientificidade que, no início do século $X X$, fizeram as ciências humanas enrijeceram-se no sentido de caber nos moldes das ciências exatas, começam a mudar de rumo. A flexibilidade de abordagem defendida pelos estudos culturais permite a adoção de uma pluralidade de recursos a fim de contemplar as necessidades de uma pesquisa. Os tempos são outros e, frente às variadas realidades, vem desenvolvendo-se um jeito complexo de olhar onde não parecem caber mais definições e classificações dominantes. Tudo é relativizado em um movimento que abre outras possibilidades de leitura dos fenômenos sociais que se multiplicam (LEITE, 1995).

Mas a questão é: mesmo estando instaurado o discurso de que a contemporaneidade não se encontra mais impregnada apenas por sentimentos racionalistas e funcionalistas ainda é muito comum depararmos com situações concretas que tendem a aplainar os desejos, descolar a experiência da prática e descartar as subjetividades dos processos de pesquisa instaurando um altar que ostenta a soberania absoluta da ciência sobre os sentidos.

Conectar-se às forças caóticas da vida, que contagiam o pensamento, exige coragem de se libertar de um modelo profissional de seu exercício. Um modo de conhecimento escoltado por um saber formal, capaz de articular discursos competentes e desonestos do ponto de vista existencial. Varrem-se as inscertezas, isolam-se as ideias estranhas, inclassificáveis, evita-se qualquer sensação de desamparo. Enxota-se a vida para o outro lado da calçada, procurando neutralizar os percalços que significa viver. Faz-se de tudo para não desalinhar o cotidiano. Encarna-se um tipo de subjetividade de prontidão, incapaz de aderir ao risco que é estar vivo e pensar (PRECIOSA, 2010, p. 27).

O pertencimento a este universo acadêmico instaura em mim desejos de pesquisar sem separar e cancelar caminhos, mas riscar para fora do prumo e abrir outros trieiros. Essa movimentação vai ressaltando uma posição de sujeito "que se encontra ao mesmo tempo dentro e fora do discurso dominante" (VERSIANI, 2005, p. 214).

Como exercício de experimentação metodológica, meus encontros de ordem epistemológica, eu organizo à maneira deleuziana (1988) de modo que se cumpram através de um pensamento cambiante e inacabado. 
A noção de multiplicidade deleuziana é realizada através de agenciamentos que "vão na contra-corrente da estabilização, da solificação, da estratificação" (SILVA, 2004, p. 38). Em meu processo de doutoramento, as várias possibilidades de encontros desencadeados por minha pesquisa, acabaram criando itinerários. Buscando visualizar o conjunto de vias abertas por esses encontros, reuni fotografias, documentos, desenhos, observações e os organizei em uma coleção de visualidades montadas em uma parede da minha casa (Figura 2). Uma montagem por onde pude conectar pessoas a lugares, lugares a histórias, histórias a imagens, imagens a ideias, dúvidas, descobertas e toda sorte de vislumbramentos.

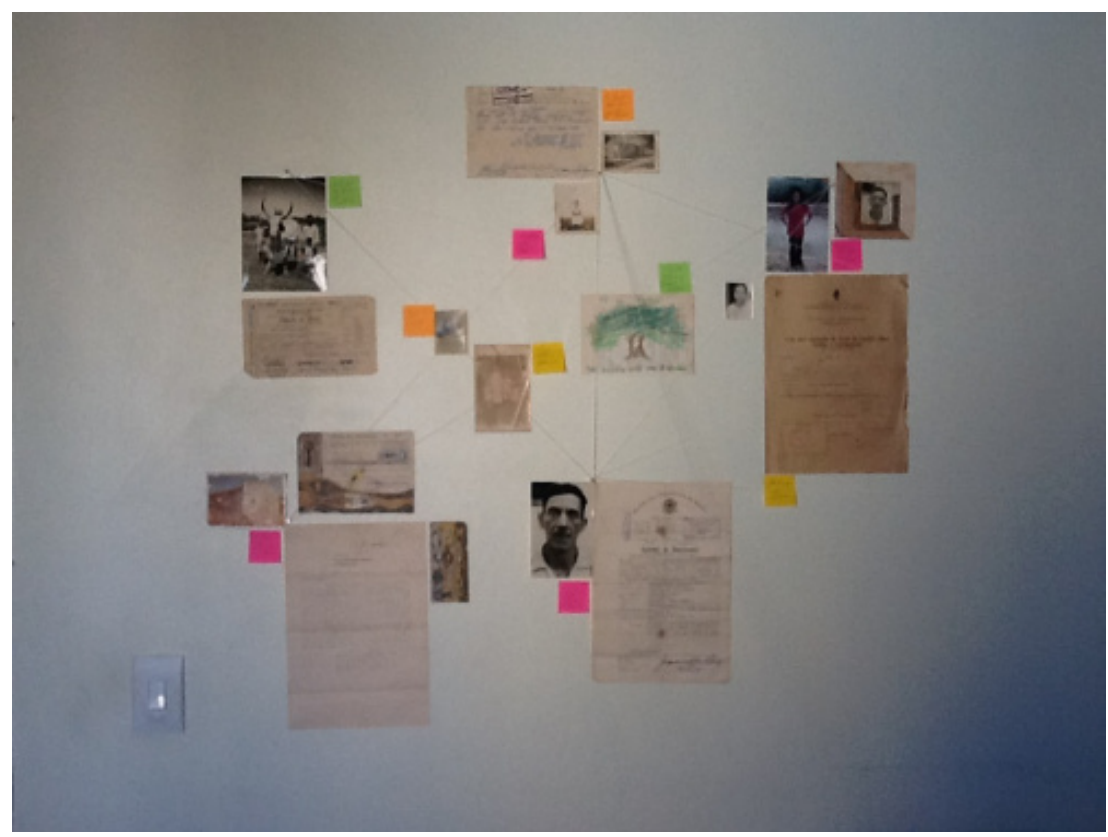

Figura 2 - Painel de visualidades onde são traçados os itinerários percorridos em parte da pesquisa (foto do autor).

Ao trançar linhas para vincular diferentes associações a cada uma das visualidades desse meu conjunto, foi lentamente se configurando em mim uma ideia de constelação como uma possibilidade de entendimento dessa movimentação metodológica. A imagem como o lugar de um processo vivo, também participa de um sistema de pensamento (SAMAIN, 2012). Ao olhar esta composição percebi que, nela, havia bem mais do que só as imagens que eu fui ajuntando pelo caminho. Observei que sua ordenação se desdobrava em possibilidades tantas que era como um olhar que se lançava para o céu estrelado e, à partir do tamanho, brilho e intensidades de cada estrela, pudesse escolher qualquer uma delas para a montagem de novas imagens, novos traçados e outros desenhos particulares. Abracei essa inquietação com muito mais convicção depois de ler o conto “Missa do Galo (Variações sobre o Mesmo Tema)" de Lygia Fagundes Telles: 
Agora tem o céu apertado de estrelas com os escuros pelo meio ocos que procuro preencher com minha verdade que já não sei se é verdadeira, há mais pessoas na casa. E fora dela. Cada qual com sua explicação para a noite inexplicável. Matéria imperecível no bojo do tempo (TELLES, 2010, p. 115).

As palavras ressoaram em mim por um tempo e me fizeram perguntar com mais veemência: O que há nos "escuros" do meu atlas estelar? Quais são suas maneiras de me fazer pensar? Como posso me valer desses intervalos para mapear conceitos para o desenvolvimento da minha pesquisa?

Ao me lançar nesses escuros em busca de lacunas de significação, encontrei nesse "oco", a possibilidade de estabelecer um jogo de forças que se cruzam de modo relacional e sem a rigidez de um encadeamento lógico que funcione para todos do mesmo modo. De forma mais clara, essa reflexão foi se adensando quando meu atlas particular encontrou aporte na perspectiva do Atlas Mnemosyne, último e inacabado projeto de Aby Warburg. Um conjunto de imagens que reunia em diferentes papéis, reproduções dos seus temas favoritos da história da arte, mas também imagens publicitárias, selos, fotografias de imprensa... Uma constelação feita a partir de aproximações intuitivas entre imagens, textos e símbolos em uma espécie de "atlas complementar de uma memória" (Rocha Peixoto, 1975, p. 403).

Mnemosyne é uma espécie de enciclopédia de movimentos em constantes andanças no tempo, de tensões e de outros afetos que se inscrevem e habitam o inconsciente da memória humana coletiva, tal como camadas geológicas. A única diferença com relação às camadas superpostas das rochas é a maneira como vivem, sobrevivem e se configuram esses movimentos expressivos do destino humano, com suas fundamentais inquietações existenciais (SAMAIN, 2012, p. 56).

Ao propor a interação entre imagens tão díspares, como por exemplo, uma certidão de nascimento e um chapéu de feltro, essa ideia de aproximação me permite reunir objetos afastados no tempo e no espaço. Georges Didi-Huberman (2013) insiste que este projeto, que Warburg definiu como teoria da função da memória humana através de imagens, se distinguiria absolutamente de um inventário. Mnemosyne não seria um arquivo, mas um trabalho anamnese por apontar percursos temporais que não são lineares e determinados. "São caminhos e trajetos sim, circulares, indefinidos e infinitos, policrônicos, transitórios e transterritoriais" (SAMAIN, 2012, p. 59).

Não sendo inventário ou arquivo, minha aproximação com as discussões relacionadas ao atlas de Warburg, me fez investigar quais seriam os aspectos formais que conferiam esta dinâmica a um conjunto de visualidades? Se pegarmos o próprio Warburg como exemplo, veremos que seu projeto reunia cerca de 2.000 imagens sem legenda e aglomeradas em um painel onde o desdobramento das suas relações não é arbitrário (Figura3). As 
imagens, presas a ecrãs com pinças manipuláveis, abrem intervalos no fundo negro que não é só uma superfície onde se dispõe o quebra-cabeças, mas é parte do próprio. DidiHuberman (2013, p. 496) vê esse intervalo negro como servindo de "fundo e de passagem" às imagens entre elas - ele é o "meio das imagens, uma atmosfera visual" que se reflete nelas. É a "armadura visual" da montagem, o tecido engendra as ligações entre as diferentes imagens - com todos os esquecimentos e inconscientes que também as determinam.

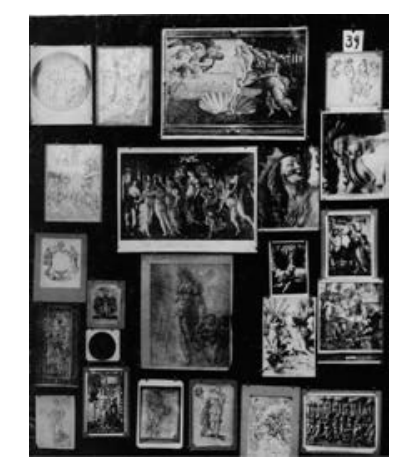

Figura 3 - Parte do painel de Aby Warburg

(I magem capturada em http://www.aisthesisonline.it/2010/2-2010/i-warburg/) .

Esse fundo também corresponderia ainda ao intervalo criado pelo imprevisível vaivém das visualidades que, sendo fruto de encontros, são rearranjadas segundo as alterações de percurso e todas as associações inesperadas e seus respectivos contextos provisórios.

Como sugere Didi-Huberman, a imagem é feita de sentidos, mas não só: "uma das grandes forças da imagem é a de produzir ao mesmo tempo sintoma (ruptura dentro do saber) e conhecimento (ruptura dentro do caos)" (DIDI-HUBERMAN, 2013, p. 31). Dentro do processo de significação das imagens coexiste um resultado e também uma perturbação.

Com um trajeto contingente, meu pequeno atlas está aberto às singularidades de um contexto em mutação constante. O caráter transitório e movediço do traçado que eu fui criando entre uma visualidade e outra contém tanto as permanências que me serviram para compor minha reflexão, quanto a possibilidade de outras ordenações em outros tempos e ocasiões. É, portanto, espaço de diálogo e de inter-relações que, no meu caso, foram direcionadas pelo trabalho da memória. "As imagens gostam de caçar na escuridão de nossas memórias. São infinitamente menos capazes de nos mostrar o mundo que de oferecê-lo ao nosso pensamento" (SAMAIN, 2005, p. 15).

No Livro das Passagens, Walter Benjamin (2006, p. 478) definia a imagem dialética como o ponto onde um "Outrora encontrava um Agora" produzindo um clarão e formando uma constelação. Tal como o agora e o outrora de Benjamin, tal como a matéria e a forma de 
Warburg, tal como as estrelas e o que há entre elas, a imagem compreende tanto um acontecimento como uma eternidade (NANCY, 2003).

Que espécie de movimento é este atribuído às imagens que escapa à sequência cronológica. Para Warburg, a imagem é um organismo enigmático, que longe de ser inerte e inanimado é dotado de uma vida. Ao longo da sua transmissão histórica, ela é ora transmitida, ora esquecida, ora redescoberta, ela atravessa períodos de latência e de crise, repete-se e metamorfoseia-se.

A cadência desse movimento tensivo e anacrônico só pode ser entendida a partir do jogo indivisível entre inconscientes e conscientes, entre latências e crises, entre o que é esquecido e o que é lembrado, o que é relembrado e reesquecido.

Assim sendo, os conceitos que emergem desse movimento não devem ser abandonados em seu momento temporal, mas que esse seja ressignificado a cada momento dentro de um plano imanente qualquer. É preciso que se entenda conceitos como dialética, como ideia descontinuada ligada a um momento de criação, de ressignificação (DELEUZE, 1997). Tudo impulsionado pela necessidade de cada momento histórico, de cada pensamento nômade.

\section{Fragmentos e caprichos de uma filosofia produtora}

O pensamento de Deleuze e Guattari também propõe uma filosofia produtora e não somente reflexiva e interpretativa. Ao vislumbrar procedimentos fragmentados, esse pensamento vislumbra uma certa relativização dos cânones universais para que se tornem imanentes, de modo que se relacionem com a permanência do ser no mundo. $A$ grosso modo, para Deleuze e Guattari, os conceitos passariam a responder a circustâncias, tirando-os da sua condição de essência das coisas, de universais.

Diante do meu atlas, o papel da imagem foi se reconfigurando e passando de pequenos pontos a um sistema complexo. O impacto desta experiência alude a possibilidade dessa montagem em despertar reflexões e propor caminhos metodológicos singulares. Desenhar e redesenhar ações através dessa constelação é uma de minhas propostas na tentativa de refletir sobre o processo no qual as conexões que estabeleço entre as imagens funcionem como eixo deflagrador de experiências educativas.

Obedecendo a primeira ordenação das imagens desse meu atlas, foi possível traçar três operações possíveis envolvendo conexões diferenciadas entre suas partes e, com isso, rabiscar novos itinerários e destacar pontos de discussão para a pesquisa. Os conceitos sobre os quais minha pesquisa está montada foram aparecendo pelo entrecruzamento 
dessas operações num jogo fragmentado e incerto que tento, aos poucos, encadear numa escrita que dê conta desses devires.

As relações de uma visualidade com outra são assim tecidas não só pelas imagens que veicula ou pela história das imagens que elas contêm, mas também pela sua utilização, isto é, pelas histórias particulares da sua apropriação.

Para Warburg, a imagem é uma teia de resíduos vitais da memória (DIDI-HUBERMAN, 2013, p. 310), constituindo-se como o órgão da memória social. Vemos uma imagem não só como imagem recortada do mundo, mas também como imagem que se vai reinscrevendo no mundo e que vai sendo reinscrita.

Uma imagem que, por si só já é o cruzamento de um movimento e instante singulares com uma imobilização reprodutível. Marca de uma viagem singular, cada visualidade revela um percurso, um movimento dinâmico recheado de temporalidades. Tecem um vaivém entre fragmentos de uma narrativa privada e singular aos fragmentos de outras narrativas, coletiva, plural.
A imagem é da ordem da suspensão (a forma, o presente, a representação) e da ordem do movimento (a força, o aparecer e desaparecer). (...) Por isso ela envolve tanto a proliferação indefinida de imagens como seu isolamento, a moldura na parede (NANCY, 2003, p. 178).

As visualidades, contidas e construtoras desse atlas, estabelece relações incalculáveis com outras imagens, desdobrando estas relações ao longo do trajeto e contexto singulares de cada momento da pesquisa. Um ritmo onde anacronias, conscientes e inconscientes, esquecimento e lembrança se juntam, entrelaçam, intrincam indissoluvelmente.

Tarefa nem sempre fácil de fazer, ou mesmo de acompanhar, refletir contemporaneamente sobre estas camadas cambiantes é permear esta reflexão pelas condições de visibilidade e levar em consideração que esse sistema é aberto e, desse modo, também se completa por outros modos de ver. Presumo ser necessário esse reconhecimento porque pressupõe refletir metodologicamente os processos de interação e negociação entre sujeitos, a começar pelo meu papel como pesquisador que passa a re[ver] a própria participação e atuação nesses processos. A meu ver, a noção constelar que envolve a configuração desse atlas de imagens é também uma espécie de experimentação por onde as institucionalidades ligadas ao enrijecimento das metodologias podem ser trituradas mediante as inúmeras vias de acesso que esse tipo de montagem deixa entrever. 
Nem sempre é confortável escolher uma destas vias e tampouco dá para sair ileso destes cruzamentos, pois eles amarram encantamentos e frustrações em uma mesma medida e seus mapeamentos, sejam eles concretos ou abstratos, representam desenhos intrincados, cartografias produzidas ao longo dos percursos da vida.

Pela minha experiência, tais mapeamentos possuem relação direta com enfoques produtivos, pois misturam afetos, produção de sentidos e, conseqüentemente, geram narrativas. Uma realidade que é constantemente transformada e recriada. Esta tarefa também se configura num exercício de imaginar. O diálogo entre imaginação e realidade é ponto fundamental para as possíveis conexões entre uma visualidade e outra desse atlas. Esse jogo evidencia modos de atuar, de me desenhar e pensar as investigações como práticas relacionais repletas de imbricações e, por que não dizer, de diversões. "O conhecimento não pode ser considerado uma ferramenta ready-made, que pode ser utilizada sem que sua natureza seja examinada" (MORIN, 2000, p. 14).

Ajustar abordagens inventivas e divertidas vai na contramão do pensamento reducionista de que é preciso um certo sofrimento para que o aprendizado seja efetivamente concretizado.

A fragilidade intelectual e emocional que nos acomete quando temos que enfrentar as metodologias, em nossas investigações, é fruto do endeusamento desse tipo de pensamento a que denominamos ciência e que está impregnado de parâmetros que enquadram todos, homogeneízam tudo, definindo o certo e o errado, o bom e o mau, o falso e o verdadeiro, etc (COSTA, 2007, p.18).

A possibilidade de atribuir novos modos de fazer em torno de nossas práticas investigativas, circunscreve posturas necessárias em torno do estabelecimento de diálogos com meus diferentes papeis de atuação num movimento alternado e contínuo que vai descortinando contextos variados. Afinal, "nós não simplesmente vemos, nós vemos como, em relação, em termos, a respeito, à luz..." (BASTOS, 2005).

Segundo Freedman (2006), a abordagem pedagógica entre o "ver" e o "fazer" se dá pelas características cognitivas das interações contíguas entre aqueles que vêem e o que é visto, explorando questões de como é que nós construímos imagens ao mesmo tempo em que elas nos constroem. Uma troca de informações, onde se ensina e se aprende usando diferentes modos de representar e significar a realidade circunscrita (CANCLINI, 1979), pois o percurso que fazemos se movimenta, permanentemente, em transformações variadas. "O que somos, o que temos sido, o que deixamos de ser, tudo é efeito do modo como vamos operando as coisas, com as coisas, nas coisas que nos acontecem" (VILELLA, 2009, p. 3). 
Ao tentar me debruçar na tessitura desse mostruário pessoal e suas variadas disposições como experiência educativa, passo a compreender os intervalos desta constelação como espaços para novas aparições sempre abertas à subjetividade de cada significado que dela se soltar.

Se admitirmos que a imagem (toda imagem) é um fenômeno, isto é, "algo que vem à luz [phanein]", "algo que advém", de um "acontecimento" (um "advento", como melhor se dizia outrora), entender-se-ia que ela é, ainda, uma "epifania", uma "aparição" [epiphanein], uma "revelação", no sentido até fotográfico do termo (SAMAIN, 2012, p.30).

O atlas que apresentei aqui não nos revela apenas a sintonia do trânsito destas molduras móveis que conectam memória individual com memória coletiva. Mais do que isso, este atlas e seus intervalos evidencia que as relações provisórias entre todos os pontos do céu (mundo), nos seus percalços, acasos e no seu permanente devir, tem uma simetria e anacronia, a tensão e a complexidade das relações engendradas pela memória, tal como ela foi entendida por Benjamin e Warburg.

À semelhança de Mnemosyne que foi definido por Warburg como uma "história de fantasmas para adultos" (Didi-Huberman, 2013, p. 88), este atlas de visualidades desdobra vias complexas e difusas, que assustam, mas também deixam entrever brechas para respiros e contentamentos. Cruzando a nossa vida com a vida das imagens (SAMAIN, 2012), esses intervalos, em movimento constante, ecoam coordenadas incertas, por onde trafegam aquela mesma vontade menina de fazer o mundo caber e, ao mesmo tempo, se derramar de dentro de uma lata de Leite Ninho.

\section{Referências}

BASTOS, Flávia M. C. Celebrando autorias: arte, comunidade e cotidiano em arteeducação. Visualidades: Revista do Programa de Pós Graduação em Arte e Cultura Visual. Goiânia: v. 3, n. 1, p. 70-85, jan./jun. 2005.

BENJ AMI N, W. Passagens. Trad. de Irene Aron. Belo Horizonte: Editora da UFMG, 2006.

CANCLINI, Nestor G. A produção simbólica. Teoria e metodologia em sociologia da arte. Rio de Janeiro: Civilização Brasileira, 1979.

COSTA, M.V. Novos olhares na pesquisa em educação. In: COSTA, M.V (Org.) Caminhos I nvestigativos I. 3a edição. Rio de Janeiro: Lamparina, 2007. pp. 13-22. 
DELEUZE, G. O Abecedário de Gilles Deleuze. Realização de Pierre-André Boutang, produzido pelas Éditions Montparnasse, Paris. No Brasil, foi divulgado pela TV Escola, Ministério da Educação. Tradução e Legendas: Raccord, 1988-1989.

Mil Platôs, V. 5. São Paulo-SP: Editora 34, 1997.

DIDI-HUBERMAN, Georges. A imagem sobrevivente - história da arte e tempo dos fantasmas segundo Aby Warburg. Rio de Janeiro: Contraponto Editora, 2013.

FREEDMAN, Kerry. Enseñar la cultura visual: curriculum, estética y la vida social del arte. Barcelona: Octaedro Ediciones, 2006.

LEITE, J. S. Para além do Moderno. In: Estudos em Design, v. 3, n. 1, p. 109-121, jul. 1995.

MORIN, E. Os sete saberes necessários à Educação do Futuro. São Paulo: Cortez, Brasília: Unesco, 2000.

NANCY, Jean-Luc. Au fond des images. Paris: Galilée, 2003.

PRECIOSA, R. Rumores discretos da subjetividade - Sujeito e escritura em processo. Porto Alegre: Sulina: Editora da UFRGS, 2010.

ROCHA PEIXOTO, A. A. A arqueologia e a etnografia nos bilhetes postais in Obras, Volume III. Póvoa de Varzim: Câmara Municipal, 1975

SAMAIN E. (Org.) Como pensam as imagens. Campinas, SP: Editora da Unicamp, 2012.

SILVA, T. T. da. A filosofia de Deleuze e o currículo. Goiânia: Coleção Desenredos n. 1, Faculdade de Artes visuais, 2004.

TELLES, L. F. A estrutura da bolha de sabão: contos / Lygia Fagundes Telles; Posfácio de Alfredo Bosi. São Paulo: Companhia das Letras, 2010.

VERSIANI, D. G. C. B. Autoetnografias: conceitos alternativos em construção. Rio de Janeiro: 7 letras, 2005.

VILELLA, M. Aproximações entre a arte, a estética, a formação e a pedagogia. In: II Congresso de Educação, Arte e Cultura - CEAC, 2009, Santa Maria, Anais. Santa Maria: 2009. 
Wolney Fernandes (UFG/GO)

Mestre em cultura visual e aluno do doutorado em Arte e Cultura Visual pela Universidade Federal de Goiás (UFG). Entre um certo grau de incerteza e outro de puro contentamento, transita pelos trieiros da arte guiado por imagens desenhadas pelos afetos. Um sujeito em fluxo, tateando preâmbulos de uma trajetória guiada pelos encontros. Por eles, segue rabiscando paisagens plurais, forças singulares e suspiros singelos. Endereço institucional: Faculdade de Artes Visuais/FAV Universidade Federal de Goiás-UFG Campus Samanbaia (Campus II) - Av. Esperança, s/n, Setor Itatiaia GoiâniaGO 74001-970. Endereço eletrônico: wolney7@gmail.com

Recebido em: 25/07/2014

Aprovado em: 08/08/2014 